\title{
A novel type of cosavirus from children with nonpolio acute flaccid paralysis
}

\author{
Yan Yang ${ }^{1 *}$, Aiping $\mathrm{Ju}^{2}$, Xiaofen $\mathrm{Xu}^{1}$, Xinyu Cao ${ }^{1}$ and Ying Tao ${ }^{1}$
}

\begin{abstract}
Human cosavirus (HCOSV) is a genus recently identified in the family Picornaviridae, which contains important pathogens to human health. Here, a novel type of HCoSV strain, cosavirus-zj-1 (GenBank no. KX545380), was identified in the fecal sample of a child with nonpolio acute flaccid paralysis (AFP) in China. Phylogenetic and sequence analyses suggested that this virus strain belonged to a new genotype in HCoSV B species. Our data show that surveillance of HCOSV is necessary for detecting viral agents in children with AFP, despite being the low detection rate.
\end{abstract}

Keywords: Human cosavirus, Complete genome, Phylogenetic analysis

\section{Findings}

Human Cosavirus (HCoSV) is a new member in the Picornaviridae family. It was originally detected from fecal samples of both healthy children and non-polio acute flaccid paralysis (AFP) patients in Pakistan and Afghanistan as well as in a fecal sample of a 64-year- old woman from Scotland $[1,2]$. Subsequently, many studies on $\mathrm{HCoSV}$ detection in children and adults in different countries were reported [3-9].

Besides the apparently wide geographic distribution, HCoSV has a wide genetic diversity. The genome of $\mathrm{HCoSV}$ is about $7.6 \mathrm{~kb}$ long organized in a typical picornavirus genome, the only difference is the absence of the leader (L) sequence [1]. The genome encodes four structural viral proteins (VP4, VP2, VP3, and VP1), and nine nonstructural proteins $(2 \mathrm{~A} 1,2 \mathrm{~A} 2,2 \mathrm{~B}, 2 \mathrm{C}, 3 \mathrm{~A}, 3 \mathrm{~B} 1$, $3 \mathrm{~B} 2,3 \mathrm{C}$, and $3 \mathrm{D})$ [1]. Based on the VP1 sequences, the genus is currently divided into six genetically distinct species (A-F) including more than 30 genotypes [10]. Similar to cardioviruses, which are close relatives of picornaviruses, HCoSV was frequently detected in the feces of symptomatic as well as asymptomatic subjects, and thus their role in human enteric disease remains unclear. This is partly because there have been only a

\footnotetext{
* Correspondence: jszj_yangyan@sina.com

${ }^{1}$ The Fourth Affiliated Hospital of Jiangsu University, 20 Zhengdong Road,

Zhenjiang, Jiangsu 212001, China

Full list of author information is available at the end of the article
}

limited number of epidemiological studies on this emerging virus.

In the present study, a total of 29 fecal samples were collected from 29 children between January 2010 and December 2014 with clinical manifestations of AFP but no detection of poliovirus. RT-PCR method was used to amplify a 316-nucleotides fragment of the $5^{\prime}$ non-coding region of the $\mathrm{HCoSV}$ genome [1]. Of the 29 fecal samples investigated, only one was positive for $\mathrm{HCoSV}$. The PCR products were T-A cloned, sequenced and then compared to the NCBI nucleotide collection using BLASTn. This revealed that the 316 nt HCoSV fragment shared highest sequence identity (86\%) with a viral sequence belonging to $\mathrm{HCoSV}$ A species (HCoSV-A1, FJ438902). In order to get the full genome of this divergent $\mathrm{HCoSV}$ strain and investigate whether this fecal sample also contain other viral pathogens, viral metagenomic method was used to detect the viral nucleic acid in this sample as previously reported [11].

The viral metagenomic sequencing of the HCoSVpositive fecal sample produced a total of 810,928 raw sequence reads using the Illumina MiSeq platform $(2 \times$ 250 cycles), of which 432 were identified as HCoSV by BLASTx search. The 432 HCoSV sequence reads were de novo assembled using Geneious 8.0 resulting in three contigs covering $75.2 \%(5369 / 7132)$ of the complete genome of $\mathrm{HCOSV}$. Also identified in the metagenomic dataset were 24 anellovirus reads. The anelloviruses are endemic worldwide and present in many different tissues 
[12], but there is, as of yet, no proof that anelloviruses cause any disease. Therefore, the anelloviruses in the fecal samples was not considered to be the causative agents of the APF in the present study. The near complete genome of the HCoSV was then obtained by $\mathrm{PCR}$ to bridge sequence gaps based on the three HCoSV sequence contigs assembled from viral metageomic data.

The nearly complete genome of $\mathrm{HCoSV}$ identified here was $7132 \mathrm{bp}$ long and has been tentatively named cosavirus-zj-1 with a GenBank accession number of KX545380. A pairwise comparison of the near-genome sequence showed that cosavirus-zj-1 had the highest nucleotide similarity $(67.8 \%)$ with an HCoSV B strain (FJ438907) that was identified from children with AFP in Pakistan [1]. This HCoSV encodes a 2131 aa polyprotein. Sequence analysis indicated the polyprotein, P1 protein, and $2 \mathrm{C}+3 \mathrm{CD}$ protein of cosavirus-zj-1 shared the highest sequence identities of $69.0,73.9$, and $68.3 \%$, respectively, with the closest relative (FJ438907) in GenBank. The ICTV states that enteroviruses sharing $>70 \%$ amino acid identity in polyprotein, $>60 \%$ amino acid identity in P1 protein, and $>70 \%$ amino acid identity in $2 \mathrm{C}+3 \mathrm{CD}$ regions belong to the same species. Based on the criteria, the cosavirus strain identified in the present study likely belongs to a new genotype within HCoSV B species. A numerous enterovirus serotypes have been genetically characterized based on
VP1 sequence and variants showing greater than $88 \%$ amino acid identity in their VP1 have been shown to belong to the same antibody neutralization serotype [13]. Although the VP1 of cosavirus-zj-1 shared amino acid sequence identity of $70.2 \%$ with its closest relative (FJ438907), whether this cosavirus strain belonged to a new serotype of $\mathrm{HCoSV} B$ species needs further serologic study.

To determine the relationship between cosavirus-zj-1 in the present study and the other members of HCoSVs, phylogenetic analysis based on the VP1 amino acid sequences was performed. All of $\mathrm{HCOSV}$ strains with complete or nearly complete VP1 region available in GenBank were included in the phylogenetic analysis. Amino acid sequences were aligned by CLUSTALW, and phylogenetic trees were constructed using MEGA 5.0 software in Maximum likelihood method mode with 500 bootstrap replicates. Results showed that cosaviruszj-1 clustered with other three HCoSV strains, including the previous HCoSV species B strain (FJ438907), and two unpublished HCoSV sequences, KP213322 and KM516909, which were detected from feces from children in China according to the sequence annotation in GenBank (Fig. 1). The P1 protein sequence of KP213322 shared $>60 \%$ identity with HCoSV species B strain (FJ438907) and cosavirus-zj-1 in this study, we therefore also grouped them together into species B (Fig. 1).

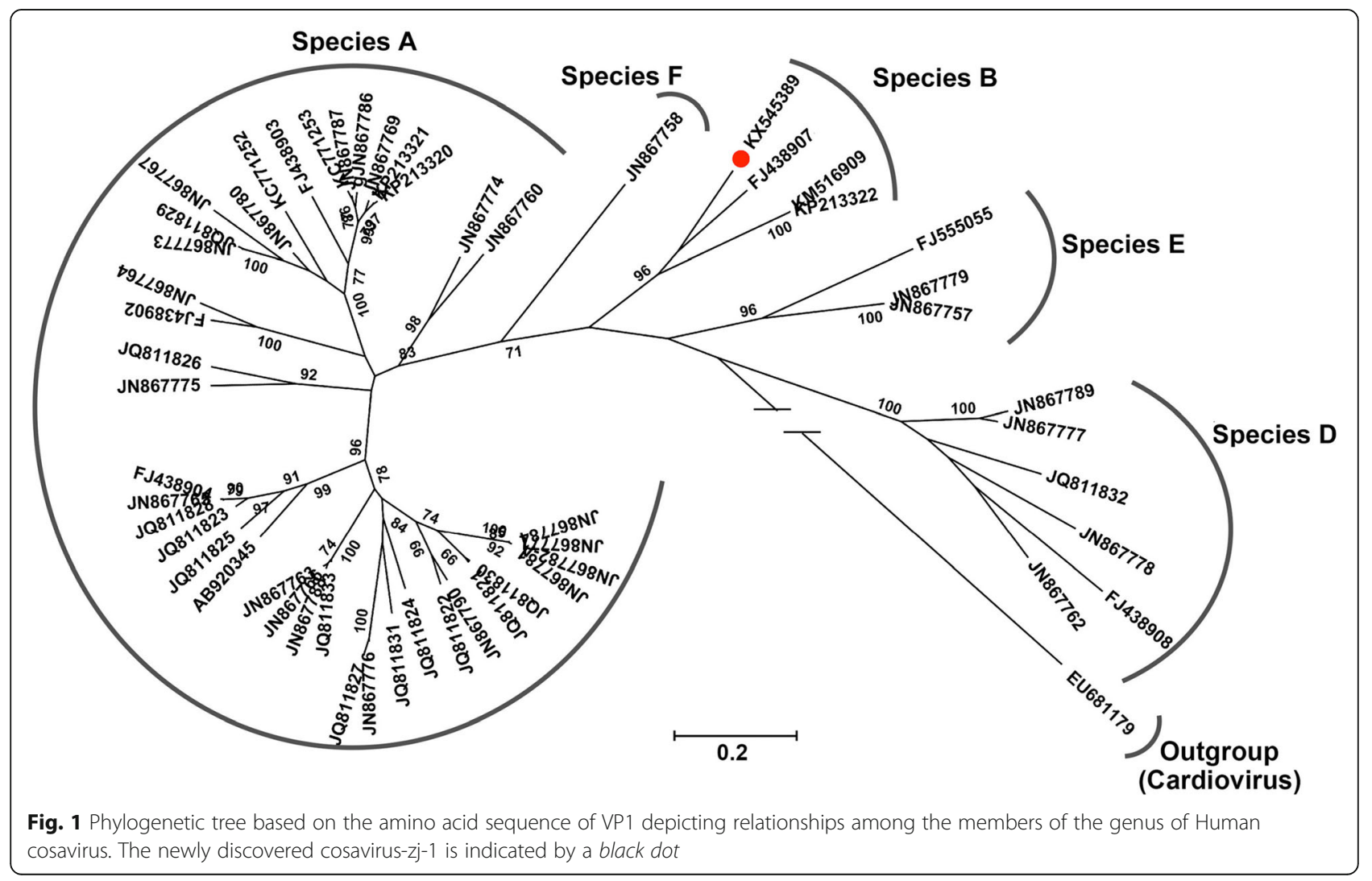




\section{Conclusion}

Taken together, we identified a cosavirus belonging to a new genotype of $\mathrm{HCoSV}$ species $\mathrm{B}$ from feces of a child with AFP in China. The cosaviral sequence in the fecal sample also confirmed by viral metagenomics which indicated that although this sample was also positive for a small number of anellovirus, cosavirus might be the cause of the AFP of this child. It is the first report of $\mathrm{HCoSV}$ species B strain was detected in a patient with nonpolio AFP in China, which suggested that surveillance of $\mathrm{HCoSV}$ is important for detecting viral agents in children with AFP, despite being the low detection rate.

\section{Abbreviations}

AFP: Acute flaccid paralysis; HCOSV: Human cosavirus; PCR: Polymerase chain reaction

\section{Funding}

This work was supported by Zhenjiang Sci-Tech Support Plan No. SH2014064 and Jiangsu Research Project for the Key Talent of Maternal and Child Health under Grant No. FRC201214.

\section{Authors' contributions}

YY and YT conceived the study. All authors participated in the experiments. YY and AJ wrote the paper. All authors read and approved the final manuscript.

\section{Competing interests}

The authors declare that they have no competing interests.

\section{Ethics approval and consent to participate}

Informed consents were provided by all participants included in the present study. Ethical Approval was given by Ethics Committee of Jiangsu University and the reference number is No. JSU2012033.

\section{Author details}

${ }^{1}$ The Fourth Affiliated Hospital of Jiangsu University, 20 Zhengdong Road, Zhenjiang, Jiangsu 212001, China. ${ }^{2}$ Department of Clinical Laboratory, Women and Children's Hospital of Huadu District, Guangzhou, Guangdong 510800, China.

Received: 18 July 2016 Accepted: 3 October 2016

Published online: 12 October 2016

\section{References}

1. Kapoor A, Victoria J, Simmonds P, Slikas E, Chieochansin T, Naeem A, Shaukat S, Sharif S, Alam MM, Angez M, Wang C, Shafer RW, Zaidi S, Delwart E. A highly prevalent and genetically diversified Picornaviridae genus in South Asian children. Proc Natl Acad Sci U S A. 2008;105:20482-7.

2. Victoria JG, Kapoor A, Li L, Blinkova O, Slikas B, Wang C, Naeem A, Zaidi S, Delwart E. Metagenomic analyses of viruses in stool samples from children with acute flaccid paralysis. J Virol. 2009;83:4642-51.

3. Blinkova O, Rosario K, Li L, Kapoor A, Slikas B, Bernardin F, Breitbart M, Delwart E. Frequent detection of highly diverse variants of cardiovirus, cosavirus, bocavirus, and circovirus in sewage samples collected in the United States. J Clin Microbiol. 2009;47:3507-13.

4. Holtz LR, Finkbeiner SR, Kirkwood CD, Wang D. Identification of a novel picornavirus related to cosaviruses in a child with acute diarrhea. Virol J. 2008;5:159.

5. Dai $X Q$, Hua $X G$, Shan $T L$, Delwart EZW. Human cosavirus infections in children in China. J Clin Virol. 2010;48:228-9.

6. Maan HS, Chowdhary R, Shakya AKDT. Genetic diversity of cosaviruses in nonpolio acute flaccid paralysis cases of undefined etiology, Northern India, 2010-2011. J Clin Virol. 2013;58:183-7.

7. Khamrin P, Maneekarn N. Detection and genetic characterization of cosavirus in a pediatric patient with diarrhea. Arch Virol. 2014;159:2485-9.

8. Stöcker A, Souza BF, Ribeiro TCM, Netto EM, Araujo LO, Corrêa Jl, Almeida PS, de Mattos AP, Ribeiro Hda C, Pedral-Sampaio DB, Drosten C, Drexler JF.
Cosavirus infection in persons with and without gastroenteritis, Brazil. Emerg Infect Dis. 2012;18:656-9.

9. Rezig D, Ben Farhat E, Touzi H, Meddeb Z, Ben Salah ATH. Prevalence of human cosaviruses in Tunisia, North Africa. J Med Virol. 2015;87:940-3.

10. Kapusinszky B, Phan TG, DE Kapoor A. Genetic diversity of the genus Cosavirus in the family Picornaviridae: a new species, recombination, and 26 new genotypes. PLoS One. 2012;7:e36685.

11. Sun G, Zang Q, Gu Y, Niu G, Ding CZP. Viral metagenomics analysis of picobirnavirus-positive feces from children with sporadic diarrhea in China. Arch Virol. 2016;161:971-5.

12. Okamoto $\mathrm{H}$. History of discoveries and pathogenicity of $\Pi \mathrm{T}$ viruses. Curr Top Microbiol Immunol. 2009;331:1-20.

13. Oberste MS, Maher K, Kilpatrick DRPM. Molecular evolution of the human enteroviruses: correlation of serotype with VP1 sequence and application to picornavirus classification. J Virol. 1999;73:1941-8.
Submit your next manuscript to BioMed Central and we will help you at every step:

- We accept pre-submission inquiries

- Our selector tool helps you to find the most relevant journal

- We provide round the clock customer support

- Convenient online submission

- Thorough peer review

- Inclusion in PubMed and all major indexing services

- Maximum visibility for your research

Submit your manuscript at www.biomedcentral.com/submit 